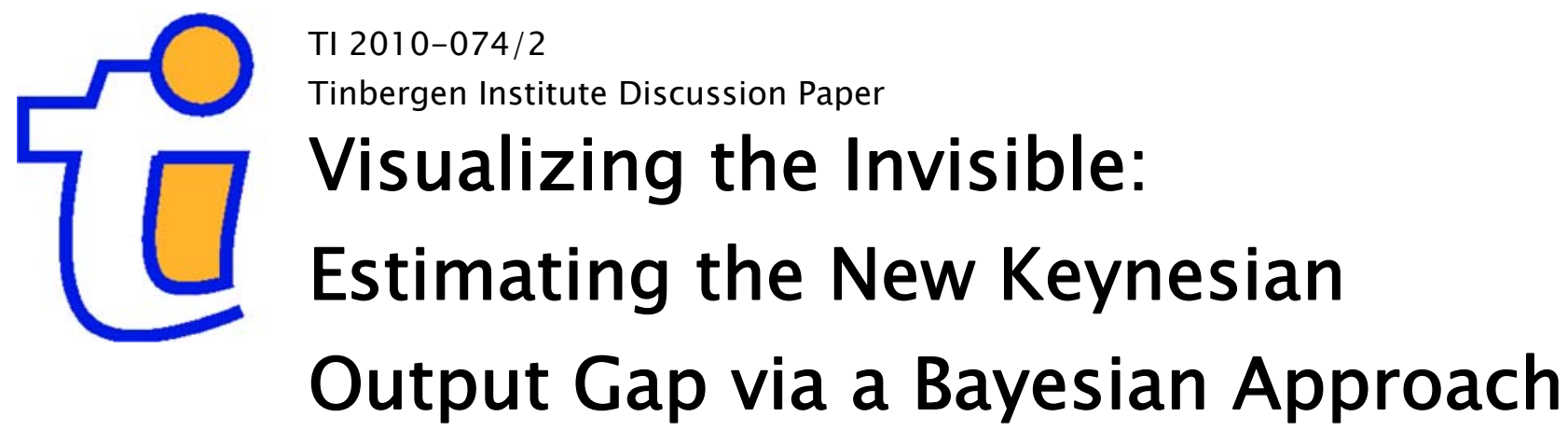

Tim Willems 


\section{Tinbergen Institute}

The Tinbergen Institute is the institute for economic research of the Erasmus Universiteit Rotterdam, Universiteit van Amsterdam, and Vrije Universiteit Amsterdam.

Tinbergen Institute Amsterdam

Roetersstraat 31

1018 WB Amsterdam

The Netherlands

Tel.: +31(0)205513500

Fax: $+31(0) 205513555$

Tinbergen Institute Rotterdam

Burg. Oudlaan 50

3062 PA Rotterdam

The Netherlands

Tel.: + $31(0) 104088900$

Fax: $+31(0) 104089031$

Most TI discussion papers can be downloaded at http://www.tinbergen.nl. 


\title{
Visualizing the Invisible: Estimating the New Keynesian Output Gap via a Bayesian Approach*
}

\author{
Tim Willems ${ }^{\dagger}$
}

March 26, 2010

\begin{abstract}
As the New Keynesian output gap cannot be observed, there is quite some debate on the question what this variable looks like. Rather than taking the standard approach of using a time trend or the HP-filter to estimate it, this paper separates trend from cycle via Bayesian estimation of a New Keynesian model, augmented with an unobserved components model for output. This provides us with a model consistent estimate of the output gap. This estimate is compared to popular proxies used in the literature. It turns out that the benefits of using the model-based approach mainly lie in real time.

Key words: Bayesian estimation; unobserved components model; New Keynesian model; output gap

JEL-classifications: C53, E32, E37, E52
\end{abstract}

\section{Introduction}

Recently, the question "How to estimate the New Keynesian Phillips curve?" (henceforth referred to as the NKPC) has been subject to considerable debate. ${ }^{1}$ The controversy mainly stems from the fact that a baseline New Keynesian model (which is for example described in Galí (2008, Chapter 3)) features a key variable that cannot

${ }^{*}$ I thank Herman van Dijk, Wouter den Haan, Christian Stoltenberg and Sweder van Wijnbergen, seminar participants at the Tinbergen Institute as well as participants of the 20th $(E C)^{2}$-conference in Aarhus for useful comments and discussions. The priors and any errors are mine.

${ }^{\dagger}$ Department of Economics, University of Amsterdam, Roetersstraat 11, 1018 WB Amsterdam, The Netherlands. E-mail: t.willems@uva.nl.

${ }^{1}$ Many of the articles cited in this paper deal with this question. 
be observed in practice: the output gap. Although the latter is often referred to in news paper contexts as the difference between actual and potential output (the level of output under full capacity utilization, on which estimates are available), it has a different meaning in the New Keynesian framework. There it is defined as the difference between the actual and natural level of output, the latter being defined as the level of output that would have prevailed if prices were fully flexible. ${ }^{2}$ This is the level of economic activity that does not exert any de- or inflationary pressures stemming from the utilization of resources. Alas, prices are not fully flexible in reality, as a result of which the natural level of output, and hence the New Keynesian output gap (NKOG), cannot be observed.

The standard approach to circumvent this problem has always been to come up with output gap proxies, such as detrended GDP or the labor income share. However, as is for example set out in a series of papers by Rudd and Whelan (2005a, 2005b, 2007; henceforth referred to as RW), the use of these proxies is not undisputed and often lacks any sound theoretical foundation.

This paper therefore takes a different route: in line with reality, I treat the NKOG and the natural level of output as unobserved variables. Then, by using data on certain observables of interest, I back out the implied series for the unobservables (via the Kalman smoother) by estimating a New Keynesian model, augmented with an unobserved components model for output, using Bayesian methods.

It turns out that the NKOG estimate obtained in this way is not too different from HP-filtered GDP, with some important qualifications to be made. First, the relative similarity between the NKOG and HP-filtered GDP stands or falls with the importance of technology shocks for explaining business cycle fluctuations. Over the sample period, technology shocks do not seem to have been the major driving force of business cycles as a result of which the NKOG estimate is quite similar to HP-filtered GDP. However, if technology shocks happen to become more important in the future, the similarity between the estimated NKOG and HP-filtered GDP may break down. Second, the HP-filter does a poor job in estimating the output gap in real time as it is then no longer able to exploit future information on GDP. Consequently, the HP-filter is unsuited to be used in monetary policy analysis. The approach developed in this paper on the other hand estimates the NKOG by combining information from a forward looking variable (the rate of inflation) with the cross-equation restrictions and rational expectations implied by the model. This is shown to improve the real time performance considerably: the root mean square of the revision errors is reduced by about 54 percent compared to HP-filtered output. This, and the fact that the

\footnotetext{
${ }^{2}$ To avoid confusion in the remainder of this paper, I will refer to the difference between the actual and natural level of output as the 'New Keynesian output gap' (henceforth, the NKOG).
} 
here-adopted approach is able to take output gap uncertainty into account, makes it potentially useful for the conduct of monetary policy.

The itinerary of this paper is as follows. First, Section 2 describes the problem one encounters in the estimation of the NKPC, which lies at the heart of the issue central to this paper. Then, Section 3 discusses the related literature, after which Section 4 describes the Bayesian estimation procedure adopted in this paper. Section 5 discusses the results of this estimation and displays the estimates of the NKOG implied by the data and imposed model structure. In Section 6, I then employ some robustness checks, after which Section 7 discusses the relevance of my results for the conduct of monetary policy. Finally, Section 8 concludes.

\section{The problem}

A basic New Keynesian model in log-linear form can be described by the following equations:

$$
\begin{aligned}
& \widehat{\pi}_{t}=\beta \mathbb{E}_{t}\left\{\widehat{\pi}_{t+1}\right\}+\frac{(1-\alpha)(1-\theta)(1-\beta \theta)}{\theta(1-\alpha+\alpha \varepsilon)}\left(\sigma+\frac{\varphi+\alpha}{1-\alpha}\right) \widetilde{y}_{t} \\
& \widetilde{y}_{t}=\mathbb{E}_{t}\left\{\widetilde{y}_{t+1}\right\}-\frac{1}{\sigma}\left(\widehat{R}_{t}-E_{t}\left\{\widehat{\pi}_{t+1}\right\}-\widehat{R R}_{t}^{n}\right)
\end{aligned}
$$

augmented with a reaction function of the monetary authority to close the model (see e.g. Galí (2008, ch. 3)). Equation (1) is the NKPC, while (2) is the dynamic IS equation.

In this system, $\pi$ represents the rate of inflation, $\alpha$ equals the capital share in output, $\theta$ is the Calvo-probability that firms are allowed to reset their price, $\beta$ is the quarterly discount factor, $\varepsilon$ is the demand elasticity for each variety, $\sigma$ equals the coefficient of relative risk aversion, $\varphi$ is the inverse labor supply elasticity, $\widetilde{y}_{t}$ is the NKOG, while $R_{t}$ reflects the nominal interest rate. $R R_{t}^{n}$ is the natural real rate of interest. $\mathbb{E}_{t}$ is the expectations operator that conditions on all information available at time $t$. Finally, lower case letters refer to natural logarithms of the underlying variables (i.e. $x_{t}=\ln X_{t}$ ), while hatted variables represent deviations from the steady state (i.e. $\widehat{X}_{t}=X_{t}-X_{s s}$ and $\widehat{x}_{t}=\ln X_{t}-\ln X_{s s}$ ).

The difficulty in estimating a New Keynesian model basically stems from two issues. First, it features the NKOG $\left(\widetilde{y}_{t}\right)$ on which no data is available as we cannot observe the natural level of output in practice.

Second, in deriving the NKPC, one has to make several assumptions. After all, the actual driving force of inflation is real marginal cost, which is proportional to 
the NKOG only under the assumption of perfectly competitive labor markets and if all firms use identical Cobb-Douglas production technologies.

The standard way to get around the problem that the NKOG is unobservable has always been to assume that the natural level of output follows a smooth trend over time. Subsequently, the output gap proxy can be obtained by applying an ad hoc time detrending or filtering method (such as the HP-filter described in Hodrick and Prescott (1997)) to log GDP. However, the key underlying assumption that the natural level of output follows a smooth trend over time lacks any theoretical foundation. In fact, the basic lesson of the RBC-literature is that the natural level of output may be quite volatile in the presence of technology shocks!

Possibly as a result of this, the ad hoc approach has often led to unsatisfactory NKPC-estimates: using quadratically detrended GDP as an output gap proxy, Galí and Gertler (1999, henceforth referred to as GG) for example estimated a negatively sloped NKPC, contrary to what theory predicts. The failure of the NKPC-estimation could however also be due to the second problem - that the NKOG is not proportional to real marginal cost.

To address both difficulties, GG (1999) and Sbordone (2002) have proposed to leave the NKPC in terms of the underlying driving force of inflation: real marginal cost. After all, in deriving the output gap-based NKPC (1), one first ends up with:

$$
\widehat{\pi}_{t}=\beta \mathbb{E}_{t}\left\{\pi_{t+1}\right\}+\frac{(1-\alpha)(1-\theta)(1-\beta \theta)}{\theta(1-\alpha+\alpha \varepsilon)} \widehat{m c}_{t},
$$

where $\widehat{m c}_{t}$ is the log-deviation of real marginal cost from its steady state value. As noted before, only if we assume that all firms use identical Cobb-Douglas production functions and that the labor market is perfectly competitive, it holds that the NKOG is proportional to the log deviation of real marginal cost from its steady state value via $\widehat{m c}_{t}=\left(\sigma+\frac{\varphi+\alpha}{1-\alpha}\right) \widetilde{y}_{t}$. Only then we can go from (3) to (1); if either assumption however fails to hold, this relationship no longer holds exactly.

In estimating the cost-based NKPC (equation (3)) one runs however into the problem that real marginal cost is unobserved as well in practice. But under the assumption of a Cobb-Douglas production technology $\left(Y_{t}=A_{t} K_{t}^{\alpha_{k}} N_{t}^{\alpha_{n}}\right)$, a capital stock that is fixed in the short run, and in the presence of a perfectly competitive labor market, real marginal cost is given by:

$$
M C_{t}=\frac{\partial T C_{t}}{\partial Y_{t}} \cdot \frac{1}{P_{t}}=\frac{\partial T C_{t} / \partial N_{t}}{\partial Y_{t} / \partial N_{t}} \cdot \frac{1}{P_{t}}=\frac{W_{t} / P_{t}}{\partial Y_{t} / \partial N_{t}}=\frac{W_{t} / P_{t}}{\alpha_{n}\left(Y_{t} / N_{t}\right)}=\frac{W_{t} N_{t}}{\alpha_{n} P_{t} Y_{t}} \equiv \frac{S_{t}}{\alpha_{n}}
$$

where $T C_{t}$ represents total costs, $P_{t}$ is the aggregate price level in the economy and $S_{t} \equiv \frac{W_{t} N_{t}}{P_{t} Y_{t}}$ is labor's share in national income. Note that the second equality 
uses the assumption that the capital stock is fixed in the short run, the third equality holds because of the assumption of perfect labor markets, while the fourth equality follows from the imposed Cobb-Douglas production technology. Hence, in percentage deviations from the steady state, we have:

$$
\widehat{m c}_{t}=\widehat{s}_{t},
$$

i.e. the log-deviation of real marginal cost from its steady state value is equal to that of labor's income share. ${ }^{3}$

GG (1999) and Sbordone (2002) have used relation (5) and have subsequently estimated the labor income share-based Phillips curve:

$$
\widehat{\pi}_{t}=\beta \mathbb{E}_{t}\left\{\widehat{\pi}_{t+1}\right\}+\lambda \widehat{s}_{t}
$$

As argued in these papers, the use of the labor income share as a proxy for real marginal cost significantly improves the fit of the NKPC: $\lambda$ now turns positive (as theory predicts), while both papers also present evidence that they are well able to replicate the behavior of past inflation from labor share data by making use of the forward-integrated version of equation (6).

However, both for theoretical as well as empirical reasons people have cast doubts on these results. From a theoretical point of view, there are several reasons to believe that relation (4) does not hold exactly: when the marginal wage is higher than the average one, when it is costly to adjust labor input, when firms hoard labor, or in the presence of variable capital utilization, equation (4) no longer holds and will generally underpredict the true procyclicality of marginal costs (see Rotemberg and Woodford (1999)).

RW (2005a; 2005b; 2007) argue that the empirical fit of the alternative labor share-driven NKPC is in fact not that good. Their objections against the use of labor's income share as a proxy for real marginal cost can be summarized as follows:

\footnotetext{
${ }^{3}$ Observe that the assumptions necessary to end up with equation (5) already imply that the output gap is proportional to real marginal cost (for that to hold, only the Cobb-Douglas production technology and the assumption of a perfectly competitive labor market are necessary). Therefore, I do not find the labor share-approach a convincing way to address the concern that the NKOG may not be proportional to real marginal cost: after all, if the conditions underlying (5) are satisfied, then the NKOG is also proportional to real marginal costs and one may as well use specification (1). It is an interesting way to avoid the problems related to the unobservability of the NKOG though, as the labor income share is observable. In fact, Neiss and Nelson (2005) present evidence that the unobservability issue is more problematic in the estimation of the NKPC than the question whether the output gap is really perfectly proportional to real marginal cost. Therefore, I abstract from the latter issue in this paper and focus on the unobservability problem instead.
} 
- the labor income share has spiked up in every post-war US recession (i.e. its behavior is countercyclical, see RW, 2005a: Figure 1). ${ }^{4}$ Although this is theoretically not impossible, they argue that this is unlikely to hold in practice as real marginal costs are generally believed to be procyclical. ${ }^{5}$ Moreover this implies that output was actually above its natural level during each postwar recession, asking for an interest rate increase by monetary authorities;

- for most VAR specifications (but not for the particular one reported by Sbordone (2002)), the discounted sum of labor shares tracks inflation rather poorly (RW, 2005a: Figure 2);

- inflation does not Granger-cause the labor share, which is implied by theory (RW, 2005a: Table 2);

- including the discounted stream of future labor income shares does not eliminate the role for lagged inflation rates (RW, 2005a: Tables 1 and 2);

- with respect to GG's (1999) result, RW (2007) argue that their key result (that the coefficient on the labor income share is significantly positive) no longer holds in newer vintages of the data. Moreover, they argue that the good fit that GG obtain in their figure 2 is primarily due to their use of a hybrid Phillips curve. In addition, Lindé (2005) argues that GG's (1999) single equation GMM-procedure is likely to produce imprecise and downward biased estimates of the slope of the NKPC (which could explain the negative slope GG found when using quadratically detrended GDP as a driving force in the NKPC);

- regarding Sbordone's (2002) result, RW argue that her method could have produced equally good results if detrended output would have been used rather than the labor income share (RW, 2005a: Figure 4).

In Galí, Gertler and Lopez-Salido (2005) and Sbordone (2005), these authors respond to the RW and Lindé (2005) criticisms: Galí, Gertler and Lopez-Salido (2005) argue that their results are - contrary to what is suggested by their critics - robust to different estimation procedures, while Sbordone (2005) rebuts RW's claim that forward looking behavior is unimportant in her model.

\footnotetext{
${ }^{4}$ The recessions of 1990/1 and 2001 formed an exception to this regularity.

${ }^{5}$ See e.g. Bils and Kahn (2000), who look at the cyclical properties of inventories, for evidence on the procyclicality of real marginal cost.
} 
All in all, it seems that the jury is still out on these issues. Without taking a stand in the above debate, one can in any case conclude that both the natural level of output and the NKOG are two important mystery guests in the New Keynesian framework. Therefore, this paper takes the opposite route by using available information on the relevant observables to back out model consistent estimates of the natural level of output and the NKOG. It does so by Bayesian estimation of a New Keynesian model, augmented with an unobserved components model for output.

\section{Related literature}

Starting with Kuttner (1994), there is an existing literature that uses unobserved component techniques to separate the cyclical component of output from its trend, using information on the rate of inflation. The differences with the current paper are twofold.

First, most of these contributions use maximum likelihood (ML) to estimate the parameters. This method is however outperformed by Bayesian estimation in small samples (Fernández-Villaverde and Rubio-Ramírez, 2004). Following recent advances in numerical simulation methods, Harvey, Trimbur and Van Dijk (2007) and Planas, Rossi and Fiorentini (2008) have therefore estimated Kuttner's (1994) model in a Bayesian way.

Second, and more importantly, all of the above cited papers do not estimate the output gap within a fully micro-founded New Keynesian setting. Kuttner (1994) and the subsequent literature rather augment the unobserved components model for output with an entirely backward looking, ad hoc Phillips curve-like relation, linking the output gap and lagged economic growth to the change in inflation. ${ }^{6}$ This paper instead estimates a very general, microfounded New Keynesian model and thus takes the cross-equation restrictions implied by this model into account.

\section{Bayesian estimation}

\subsection{The model}

To back out the series for the natural level of output and the NKOG implied by the data, I use Bayesian estimation. This approach has several advantages over other estimation techniques (Rabanal and Rubio-Ramírez, 2005): compared to single equation methods, it takes advantage of the general equilibrium approach (as it is able

\footnotetext{
${ }^{6}$ In particular, Kuttner (1994) uses $\Delta \pi_{t}=\eta+\zeta \Delta y_{t-1}+\psi \widetilde{y}_{t-1}+\varepsilon_{t}^{\pi}$.
} 
to extract information from impulse response functions and correlations implied by the data), it outperforms GMM and ML in small samples (as it is able to incorporate prior knowledge) and it does not rely on the identification scheme of the VAR.

I do not estimate the basic New Keynesian model represented by equations (1) and (2), as this system is much too restrictive. As is for example shown in Christiano, Eichenbaum and Evans (2005), allowing for both habit formation and a backward looking component in the Phillips curve is important for matching the data. Therefore, I estimate the following, much more general system instead:

$$
\begin{aligned}
\widehat{\pi}_{t} & =\gamma \widehat{\pi}_{t-1}+(1-\gamma) \beta \mathbb{E}_{t}\left\{\widehat{\pi}_{t+1}\right\}+\kappa \widetilde{y}_{t}+\varepsilon_{t}^{\pi}, \varepsilon_{t}^{\pi} \sim \mathcal{N}\left(0, \sigma_{\pi}^{2}\right) \\
\widetilde{y}_{t} & =\vartheta \widetilde{y}_{t-1}+(1-\vartheta) \mathbb{E}_{t}\left\{\widetilde{y}_{t+1}\right\}-\frac{1}{\sigma}\left(\widehat{R}_{t}-\mathbb{E}_{t}\left\{\widehat{\pi}_{t+1}\right\}\right)+\zeta_{t} \\
\widehat{R}_{t} & =\delta \widehat{R}_{t-1}+(1-\delta) \phi_{\pi} \widehat{\pi}_{t}+\varepsilon_{t}^{r}, \varepsilon_{t}^{r} \sim \mathcal{N}\left(0, \sigma_{r}^{2}\right) \\
y_{t} & \equiv y_{t}^{n}+\widetilde{y}_{t} \\
y_{t}^{n} & =\rho_{y} y_{t-1}^{n}+\mu_{t}+\varepsilon_{t}^{y}, \varepsilon_{t}^{y} \sim \mathcal{N}\left(0, \sigma_{y}^{2}\right) \\
\mu_{t} & =\mu_{t-1}+\varepsilon_{t}^{\mu}, \varepsilon_{t}^{\mu} \sim \mathcal{N}\left(0, \sigma_{\mu}^{2}\right) \\
\zeta_{t} & =\rho_{\zeta} \zeta_{t-1}+\varepsilon_{t}^{\zeta}, \varepsilon_{t}^{\zeta} \sim \mathcal{N}\left(0, \sigma_{\zeta}^{2}\right)
\end{aligned}
$$

Here, the presence of the lagged value of the output gap in the dynamic IS equation captures habit formation (Fuhrer, 2000), while the parameter $\gamma$ allows for a backward looking component in the Phillips equation. The latter can either be motivated by assuming non-rational expectations (as in GG (1999)) or by the assumption that firms that are not allowed to reset their price optimally, index their price to last period's inflation rate (as in Christiano, Eichenbaum and Evans (2005)). Although it is an effective way to increase inflation persistence, both approaches lack an explicit microfoundation as a result of which they should only be seen as reduced form solutions. ${ }^{7}$ As others have found the natural rate of interest to be rather constant over time (see e.g. King and Watson (1996) and Neiss and Nelson (2003)), I take the ex ante real interest rate $\left(\widehat{R}_{t}-\mathbb{E}_{t}\left\{\widehat{\pi}_{t+1}\right\}\right)$ as an approximation for the real interest rate gap in equation (8). ${ }^{8}$

In the above system, the NKOG $\widetilde{y}_{t}$ and the natural level output $y_{t}^{n}$ are unobserved. One can however obtain estimates of these two objects via the unobserved components approach. In particular, I use a variant of the Harvey-Clark-Watson

\footnotetext{
${ }^{7}$ Recently, Sheedy (2007) has derived this so-called "hybrid" NKPC in a microfounded way by assuming an upward sloping hazard function. Then prices set $t+1$ periods ago are more likely to be adjusted than prices set $t$ periods ago.

${ }^{8}$ Also see, among others, Lubik and Schorfheide (2004) for this approach.
} 
model, which is described by equations (10) to (12). Equation (10) first defines observed output as the sum of the unobserved output gap and the unobserved level of natural output. Then, as in Harvey (1985) and Watson (1986), I assume that the natural level of output follows an $A R(1)$-process with drift parameter $\mu$, while I allow the latter to vary over time as in Clark (1989). ${ }^{9}$

In separating the NKOG from the natural level of output, the above system uses the restrictions imposed by the Harvey-Clark-Watson model. These include the assumption that the natural level of output follows an $A R(1)$, that the NKOG is stationary, while the drift parameter $\mu$ is assumed to follow a random walk. Moreover, trend and cycle are assumed to be uncorrelated.

I add several shocks to the model. First, I allow for a persistent demand shock $\zeta_{t}$ to the dynamic IS equation and, second, I model four transitory shocks: a cost-push shock to the $\operatorname{NKPC}\left(\varepsilon_{t}^{\pi}\right)$, a monetary policy shock $\left(\varepsilon_{t}^{r}\right)$, a shock to the growth rate of the natural level of output $\left(\varepsilon_{t}^{\mu}\right)$ and a shock to the natural level of output itself $\left(\varepsilon_{t}^{y}\right)$.

I do not close the model with the familiar Taylor-rule (which assumes that the monetary authority reacts to both the inflation rate and the NKOG), but with a pure inflation targeting rule instead. This is due to the fact that current monetary authorities cannot observe the true NKOG in practice either, as a result of which it makes no sense in the spirit of this paper to assume that they respond to it. ${ }^{10}$ In the interest rate rule, the parameter $\delta$ governs the degree of interest rate smoothing as in Clarida, Galí and Gertler (2000), while $\phi_{\pi}$ is the monetary authority's reaction coefficient on inflation.

\subsection{The data}

I use quarterly data from 1954Q3 to 2008Q3 (so 217 observations), all taken from the St. Louis Fed FRED-database. The observables are the rate of inflation, the nominal interest rate and real GDP. Let the series of observables henceforth be referred to as $\left\{\mathbf{y}_{t}\right\}_{t=1954: 3}^{2008: 3}$.

\footnotetext{
${ }^{9}$ Harvey (1985) and others actually impose the natural level of output to follow a random walk with drift $\left(\rho_{y}=1\right)$, motivated by the findings of Nelson and Plosser (1982). Their conclusion is however debated. In particular, Perron (1989) and Weber (1995) argue that output is stationary around a time trend, but that this trend is subject to occasional random changes in its slope and intercept. To allow for this possibility, I estimate the more general $A R(1)$-specification (as in DeJong and Whiteman (1989)) with time varying drift parameter $\mu$.

${ }^{10}$ They rather seem to respond to something like HP-filtered output (see Clarida, Galí and Gertler (2000)). Omitting this variable is not really a problem as this only results in larger monetary policy shocks, in which I am not particularly interested here.
} 
The series for output consists of logged, annualized, seasonally adjusted data on real gross GDP. Note that I am able to feed non-stationary data into the estimation procedure; $^{11}$ there, the Harvey-Clark-Watson model separates the non-stationary trend from the stationary output gap component, using the information contained in the NKPC.

The rate of inflation is measured by taking the log-difference in the chain-type, seasonally adjusted GDP deflator and subsequently annualizing it. However, as this variable enters the estimated system in log deviations from its steady state, I do have to find a proxy for the latter. As in Schorfheide (2008), I allow for a drifting steady state level of the interest rate by assuming that it is equal to the HP-trend. Some have used the sample mean as a proxy for the steady state, but this assumes that the target interest rate has stayed constant over the past decades, which does not seem to have been the case in practice (Gerlach and Svensson, 2003). ${ }^{12}$

Finally, the nominal interest rate is the average of the effective federal funds rate that applied over the respective quarter. As the interest rate enters the estimated system in deviations from its steady state as well, I HP-filter the series and use the deviations from the HP-trend as a proxy for the deviations from the steady state. ${ }^{13}$

\subsection{The likelihood function and model estimation}

The vector of parameters is described by $\psi=\left(\beta, \gamma, \delta, \vartheta, \kappa, \sigma, \phi, \rho_{y}, \rho_{\zeta}, \sigma_{y}, \sigma_{\pi}, \sigma_{\zeta}, \sigma_{r}, \sigma_{\mu}\right)^{\prime}$. As we are dealing with a linearized model, we can write it in state-space form and evaluate the likelihood of the model by using the linear-Gaussian Kalman filter. The posterior distribution of the parameters given the data, $\mathcal{P}\left(\psi \mid\left\{\mathbf{y}_{t}\right\}_{t=1954: 3}^{2008: 3}\right)$, is equal to the product of the likelihood function $\mathcal{L}\left(\psi,\left\{\mathbf{y}_{t}\right\}_{t=1954: 3}^{2008: 3}\right)$ and the prior distributions $p(\psi)$, to be specified below. As it is not possible to obtain a closed-form solution for these objects, they are evaluated numerically. This is done with the MetropolisHastings algorithm. Results are obtained after simulating 500,000 draws, of which the first half is discarded. The model is estimated with Dynare.

\footnotetext{
${ }^{11}$ To cope with the infinite variance associated with the specified process for the natural level of output (which contains a unit root), I use a diffuse prior (with infinite variance) for the initialization of the Kalman filter.

${ }^{12}$ Inflation rates averaged to almost 7 percent during the 1970s, while this average has dropped to 2.5 percent since. See Cogley and Sbordone (2008) for more evidence on the existence of so-called "trend inflation".

${ }^{13}$ As for the inflation rate, HP-filtering the interest rate is less restrictive than demeaning as it allows for changes in its steady state. Again, this seems to have been the case in practice: the average interest rate equaled 9.9 percent from 1979Q1 to 1990Q4, while it has dropped to an average value of 4.1 percent since.
} 


\subsection{The priors}

Table 1 provides an overview of the prior distributions of the parameters. In the table, $\beta\left(\mu, \sigma, p_{1}, p_{2}\right)$ indicates a beta distribution with mean $\mu$ and standard deviation $\sigma$ over the interval $\left[p_{1}, p_{2}\right], U\left[p_{1}, p_{2}\right]$ is a uniform distribution over the $\left[p_{1}, p_{2}\right]$-interval, $\Gamma(\mu, \sigma)$ represents a gamma distribution with mean $\mu$ and standard deviation $\sigma$, while $\Gamma^{-1}(\mu, \sigma)$ refers to the same for an inverted-gamma distribution.

The prior for $\gamma$ (the backward-looking component in the NKPC) follows a beta distribution over the $[0,1]$-interval as we can exclude values outside this range for theoretical reasons. Since the for- or backward lookingness of the NKPC is still heavily debated (compare GG (1999) arguing the former, while RW (2005b) favor the latter), I stay agnostic with respect to this issue by setting the prior mean equal to 0.5 and symmetrically allowing for both up- and downward deviations from this mean.

I set the prior mean for $\delta$ equal to 0.5 , as there seems to be considerable degree of interest rate smoothing in at least the European data ( $c f$. Smets and Wouters $(2003))$.

My prior for the coefficient expressing the importance of habit formation $(\vartheta)$ is centered around 0.5, thereby allowing for a substantial role for this feature. This is motivated by the fact that other studies find habit formation to be important for DSGE-models in matching key asset market statistics (Boldrin, Christiano and Fisher, 2001). As I do not model the asset market here, I include this information in my prior. Note again that by setting the prior mean equal to 0.5, I stay agnostic on the question whether for- or backward lookingness dominates in the dynamic IS equation. 


\begin{tabular}{||l||l||}
\hline \hline & Prior distribution \\
\hline \hline$\gamma$ & $\beta(0.5,0.15,0,1)$ \\
\hline \hline$\delta$ & $\beta(0.5,0.15,0,1)$ \\
\hline \hline$\vartheta$ & $\beta(0.5,0.15,0,1)$ \\
\hline \hline$\kappa$ & $\beta(0.4,0.15,0,1)$ \\
\hline \hline$\sigma$ & $\Gamma(2,1)$ \\
\hline \hline$\phi$ & $\Gamma(1.5,0.5)$ \\
\hline \hline$\rho_{y}$ & $U[0,1]$ \\
\hline \hline$\rho_{\zeta}$ & $\beta(0.8,0.1,0,1)$ \\
\hline \hline$\sigma_{y}$ & $\Gamma^{-1}(0.01, \infty)$ \\
\hline \hline$\sigma_{\pi}$ & $\Gamma^{-1}(0.01, \infty)$ \\
\hline \hline$\sigma_{\zeta}$ & $\Gamma^{-1}(0.01, \infty)$ \\
\hline \hline$\sigma_{r}$ & $\Gamma^{-1}(0.01, \infty)$ \\
\hline \hline$\sigma_{\mu}$ & $\Gamma^{-1}(0.01, \infty)$ \\
\hline \hline
\end{tabular}

Table 1: prior distributions of parameters

Regarding the slope of the NKPC $(\kappa)$, there is little consensus in the literature yet. As surveyed by Schorfheide (2008), estimates vary from close to zero (Cho and Moreno, 2006) to 0.77 (Lubik and Schorfheide, 2004). Therefore, I set the prior mean of $\kappa$ close to the average of existing estimates - allowing for both up- and downward deviations.

I set the mean of the prior for the coefficient of relative risk aversion $\sigma$ equal to 2, which is a well-accepted value in the macro-literature. The prior mean of the Taylor-coefficient on inflation is set equal to Taylor's original (1993) value of 1.5.

For the $A R$-coefficient on the natural level of output I impose a uniform prior over the $[0,1]$-interval. I also allow for substantial persistence in the demand shock by setting the prior mean for its $A R$-coefficient $\left(\rho_{\zeta}\right)$ equal to 0.8 .

The prior for the standard deviations of all shocks follows an inverted-gamma distribution with mean 0.01 and infinite variance.

Finally, as the estimated model does not include capital, it has problems in estimating the discount factor $\beta$ (Ireland, 2004). Therefore, I calibrate this parameter and set it equal to its standard value for quarterly data, 0.99 . 


\section{$5 \quad$ Results}

\subsection{Posterior distribution and moments}

The means and standard deviations of the posterior distributions (along with the 95 percent credible intervals) of the parameters are displayed in Table $2 .^{14}$

\begin{tabular}{|c|c|c|c|}
\hline & $\begin{array}{c}\text { Prior mean } \\
\text { (Standard deviation) }\end{array}$ & $\begin{array}{l}\text { Posterior mean } \\
\text { (Standard devation) }\end{array}$ & $95 \%$ credible interval \\
\hline$\gamma$ & $\begin{array}{c}0.5 \\
(0.15) \\
\end{array}$ & $\begin{array}{l}0.3255 \\
(0.0293) \\
\end{array}$ & $(0.2762,0.3722)$ \\
\hline$\delta$ & $\begin{array}{c}0.5 \\
(0.15)\end{array}$ & $\begin{array}{c}0.7564 \\
(0.0366)\end{array}$ & $(0.6974,0.8178)$ \\
\hline$\vartheta$ & $\begin{array}{c}0.5 \\
(0.15) \\
\end{array}$ & $\begin{array}{c}0.8582 \\
(0.0524)\end{array}$ & $(0.7744,0.9430)$ \\
\hline$\kappa$ & $\begin{array}{c}0.4 \\
(0.15) \\
\end{array}$ & $\begin{array}{r}0.0013 \\
(0.0006)\end{array}$ & $(0.0008,0.0020)$ \\
\hline$\sigma$ & $\begin{array}{l}2 \\
(1)\end{array}$ & $\begin{array}{l}7.2527 \\
(1.3134) \\
\end{array}$ & $(5.1489,9.3164)$ \\
\hline$\phi$ & $\begin{array}{l}1.5 \\
(0.2) \\
\end{array}$ & $\begin{array}{l}1.3610 \\
(0.1396) \\
\end{array}$ & $(1.1423,1.5959)$ \\
\hline$\rho_{y}$ & $\begin{array}{c}1 \\
(0.5774)\end{array}$ & $\begin{array}{c}0.9441 \\
(0.0316)\end{array}$ & $(0.8987,0.9917)$ \\
\hline$\rho_{\zeta}$ & $\begin{array}{l}0.8 \\
(0.1)\end{array}$ & $\begin{array}{l}0.5355 \\
(0.0932) \\
\end{array}$ & $(0.3805,0.6867)$ \\
\hline$\sigma_{y}$ & $\begin{array}{c}0.01 \\
\text { (inf) }\end{array}$ & $\begin{array}{c}0.0064 \\
(0.0007)\end{array}$ & $(0.0052,0.0076)$ \\
\hline$\sigma_{\pi}$ & $\begin{array}{c}0.01 \\
\text { (inf) }\end{array}$ & $\begin{array}{c}0.0072 \\
(0.0005)\end{array}$ & $(0.0064,0.0079)$ \\
\hline$\sigma_{\zeta}$ & $\begin{array}{c}0.01 \\
\text { (inf) }\end{array}$ & $\begin{array}{l}0.0032 \\
(0.0007) \\
\end{array}$ & $(0.0021,0.0044)$ \\
\hline$\sigma_{r}$ & $\begin{array}{c}0.01 \\
\text { (inf) }\end{array}$ & $\begin{array}{l}0.0086 \\
(0.0004) \\
\end{array}$ & $(0.0079,0.0093)$ \\
\hline$\sigma_{\mu}$ & $\begin{array}{c}0.01 \\
\text { (inf) }\end{array}$ & $\begin{array}{c}0.0030 \\
(0.0007)\end{array}$ & $(0.0019,0.0040)$ \\
\hline
\end{tabular}

Table 2: prior and posterior distributions of parameters

Several things are to be said about these posterior results. First of all, the posteriors differ substantially from the priors. Together with the observation that all posterior standard deviations are smaller than the prior ones (with the exception of that for $\sigma$ ), this suggests that the estimated parameters are well-identified and that the data are informative about the parameters.

\footnotetext{
${ }^{14}$ Accompanying graphs are displayed in the Appendix.
} 
Second, I find a significant role for the backward looking component in the NKPC. The posterior mean of $\gamma(0.3255)$ is quantitatively very similar to the GMM-estimates in GG (1999, who found values ranging from 0.252 to 0.378 ). Moreover, as $\gamma<0.5$, I find forward looking behavior to be dominant in the NKPC.

Third, the results also attribute an important role to the lagged NKOG in the dynamic IS equation (the posterior mean for $\vartheta$ is 0.8582 ), thereby suggesting that habit formation is important to match the data. This confirms the finding by Christiano, Eichenbaum and Evans (2005) and is consistent with the FIML-estimate of Lippi and Neri (2007, who estimated this exact coefficient to be equal to 0.79 on European data).

Fourth, the estimate of the slope of the NKPC $(\kappa)$ is at the low end of the spectrum, but in line with the estimates of for example Fuhrer and Moore (1995, who estimated this parameter by ML using linearly detrended output), Ireland (2001, who used FIML on linearly detrended output) and Cho and Moreno (2006, who used FIML, detrending output with the Congressional Budget Office Measure of Potential GDP).

My estimate for the coefficient of risk aversion $(\sigma)$ is in line with other fullinformation estimates, such as Rabanal and Rubio-Ramírez (2005) and Lippi and Neri (2007), but high compared to most prior beliefs of macroeconomists.

According to the results for $\rho_{y}$, I am able to reject the hypothesis that $\rho_{y}=1$ at the 5 percent level. This contrasts with the finding of the seminal study by Nelson and Plosser (1982) but is in line with Perron (1989) and Weber (1995).

\subsection{Visualizing the New Keynesian output gap}

As emphasized before, the natural level of output, and hence the NKOG, are unobserved in the estimated system. However, one can use the Kalman smoother to construct implied series for these variables that are harmonious with the behavior of all observables, subject to the specified model equations. Hereby, the procedure will exploit the general equilibrium approach and use the information contained in the other equations (via correlations and impulse response functions).

Figure 1 plots the behavior of the model consistent NKOG estimate, along with two of its often used proxies: linearly and quadratically detrended GDP (in Figure 1 referred to as LDT GDP and QDT GDP, respectively). 


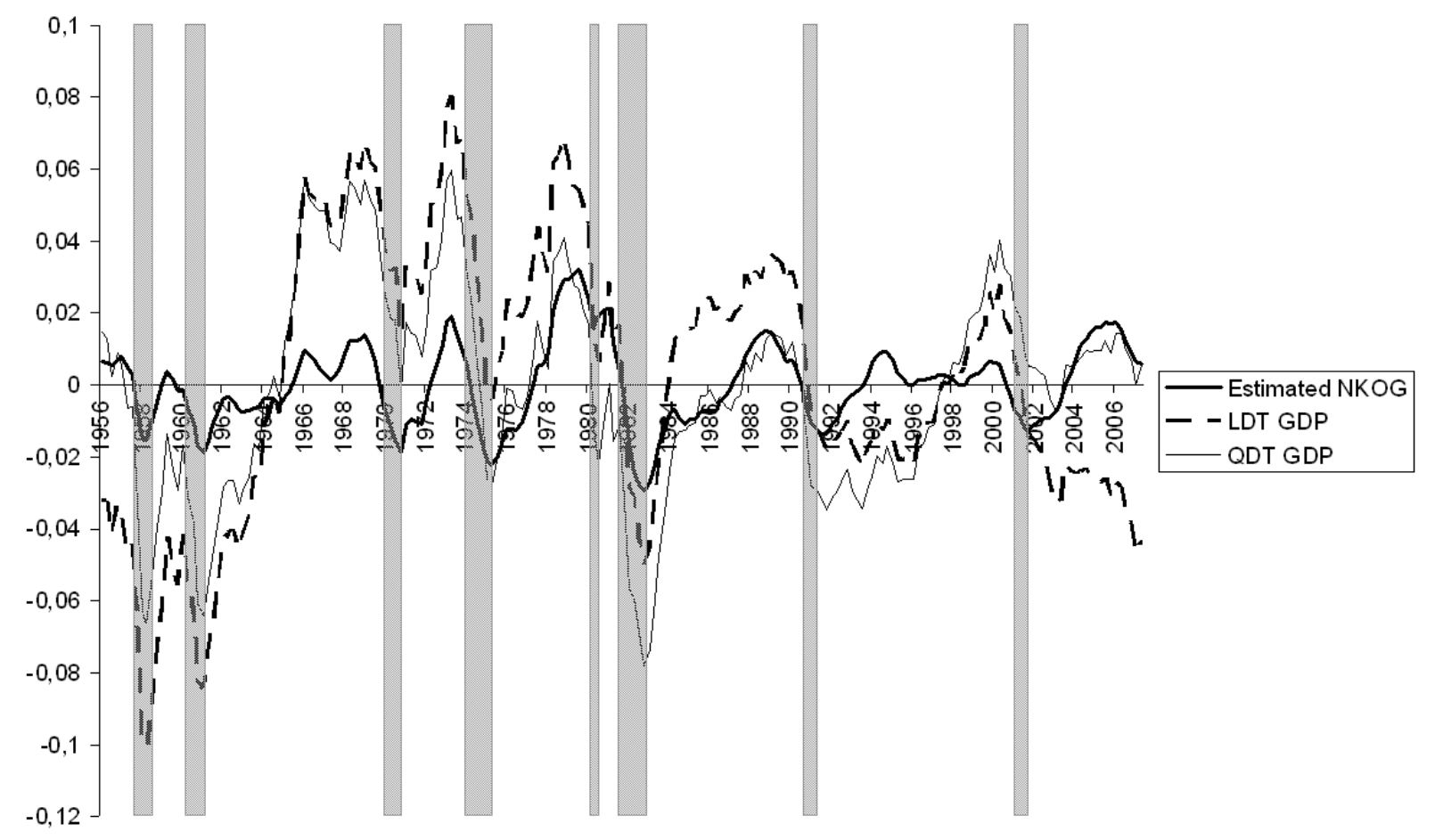

Figure 1: linearly and quadratically detrended GDP and estimated NKOG. Shaded areas correspond with NBER recession dates

Several things are to be said about this figure. First, the behavior of the NKOG estimate seems to correspond well with the widely held belief that the output gap evolves procyclically over time: during all NBER recessions, except for the 1980 one (more on which below), the NKOG turns negative - thereby justifying the lowering of interest rates during most of these periods by central banks. ${ }^{15}$ Second, also the duration and magnitude of the output gap estimate seems to correspond well with general beliefs (e.g. the 1982-gap being more negative than the one in 2001).

Figure 1 also shows that the correlation between the gaps obtained by time detrending and the estimated NKOG is far from perfect: the coefficient of correlation between the series for quadratically detrended GDP and the estimated NKOG equals 0.6196. The correlation between linearly detrended GDP and the NKOG estimate is with 0.4450 even lower. Moreover, the time detrended series have a higher amplitude. Consequently, their standard deviations are higher, equaling 0.038 for the LDT-case

\footnotetext{
${ }^{15}$ In all cases the complete 95 percent credibility band of the NKOG estimate was also below zero (see Figure A2 in the Appendix).
} 
and 0.029 for the QDT-case, while it only equals 0.012 for the NKOG estimate. This should not be that surprising as the time detrending approach assumes that the natural level of output follows a very smooth path over time - thereby attributing all business cycle fluctuations in output to fluctuations in the output gap. But as noted before, this is not the case in the face of supply shocks as these make the natural level of output volatile over time. Consequently, a central bank looking at time detrended GDP is likely to overreact to output fluctuations in setting its interest rate.

Compared to a deterministic time trend, the HP-filter allows for a stochastic and slightly more volatile trend in the underlying series. Therefore, some authors (such as Lubik and Schorfheide (2004)) have used HP-filtered output as a proxy for the NKOG. As shown in Harvey and Jaeger (1993), the HP-filter can also be seen as a univariate unobserved components model (separating the unobserved HP-trend from an unobserved HP-cycle). It does so, however, by only using data on past, current and future output. Compared to the approach taken in this paper, it thus neglects the information coming from other variables (such as the rate of inflation) as well as the cross-equation restrictions and rational expectations imposed by the New Keynesian model.

Figure 2 displays HP-filtered output (obtained by setting the HP-smoothing parameter equal to its standard value for quarterly data of 1,600) together with the NKOG estimate. This figure shows that using HP-filtered output is indeed an improvement compared to the time detrending approach: the two series move together more closely as a result of which the coefficient of correlation increases to 0.7872 . In addition, the amplitudes of the two series are much more in line: the standard deviation of HP-filtered output equals 0.015 against 0.012 for the NKOG estimate. 


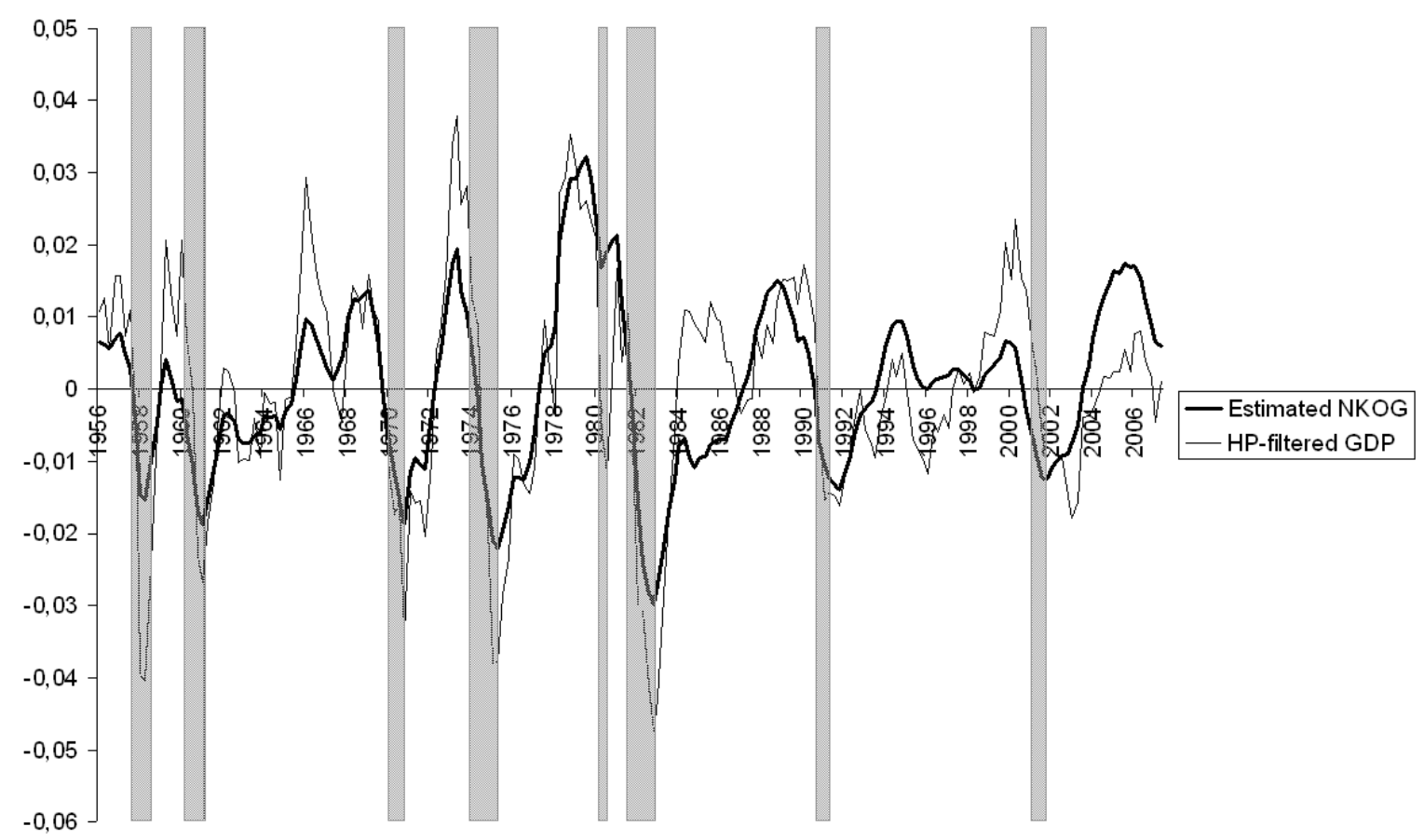

Figure 2: HP-filtered GDP and estimated NKOG. Shaded areas correspond with NBER recession dates

Nevertheless, the HP-filter imposes a path for the natural level of output that still is too smooth. This is illustrated in Figure 3: it compares the HP-trend with the estimated natural level of output in deviations from a deterministic linear time trend. ${ }^{16}$

As can be seen from the figure, the estimated natural level of output $\left(y_{t}^{n}\right)$ indeed moves rather bumpy over time, while the HP-trend just follows a smooth path through the estimated series for $y_{t}^{n}$. Quantitatively, the differences between the two series are however very small. This casts doubt on the claim that technology shocks are the main driving force of business cycle fluctuations, as one would then expect larger discrepancies between the two series. ${ }^{17}$

In this respect it is important to realize that the relative similarity between the estimated NKOG and HP-filtered GDP rests at least partially on luck: after all,

\footnotetext{
${ }^{16}$ This is done just for the sake of exposition: in raw levels, the discrepancy between the two series is harder to visualize. As a by-product, this figure also shows the difference between the estimated natural level of output and a linear time trend: it is simply the deviation of the series from the horizontal axis.

${ }^{17}$ A similar result is found by for example Smets and Wouters (2007).
} 
it really depends on the type of shock hitting the economy (supply or demand?) whether a boom (recession) is accompanied by a positive (negative) output gap. Although this seems to have been the case over the last 55 years, there is no guarantee that this will continue to hold in the future. ${ }^{18} \mathrm{~A}$ model-based approach is able to guard itself against this, while an a-theoretical detrending method is not.

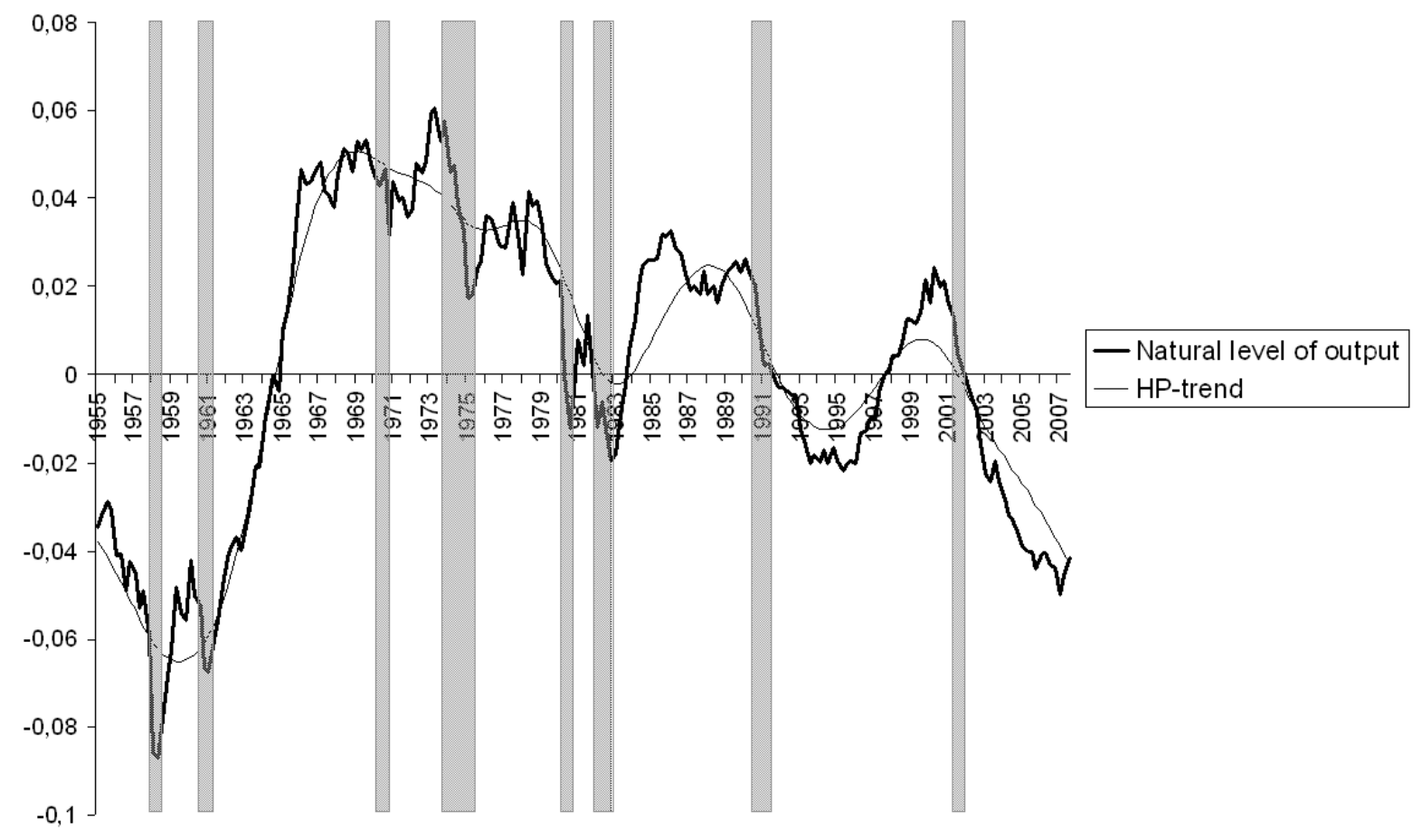

Figure 3: output's HP-trend and the estimated natural level of output in deviations from a linear time trend

Furthermore, the path followed by the estimated natural level of output corresponds with narrative accounts of supply shocks. It is for example seemingly able to pick up the oil price shocks that have occurred over the years as it shows substantial drops after 1973, 1979, 1990 and 2002 (when the latest surge in oil prices started).

Also observe that the estimates for the NKOG and the natural level of output strongly suggest that the 1980 recession was primarily due to supply shocks (quite possibly the 1979 oil price shock): after all, in 1980 the natural level of output did show a severe drop, while the NKOG remained significantly positive! Based upon

\footnotetext{
${ }^{18}$ The 1980 recession already formed an exception in this respect (more on this below).
} 
this evidence, it is not justified to characterize Paul Volcker's policy of raising interest rates at the beginning of the 1980 recession as "contractionary".

The fact that HP-filtered output does suggest a negative output gap in 1980 is likely to be due to the fact that this methods neglects information on inflation: inflation was with 9 to 11 percent unambiguously high during 1980, thereby pointing at severe inflationary pressures stemming from a positive NKOG. Univariate detrending approaches (such as the HP-filter) neglect this information, while a multivariate model-based approach does not.

Finally, would using the labor income share be another improvement, as suggested by GG (1999) and Sbordone (2002)? Figure 4 plots the NKOG estimate together with the demeaned labor income share.

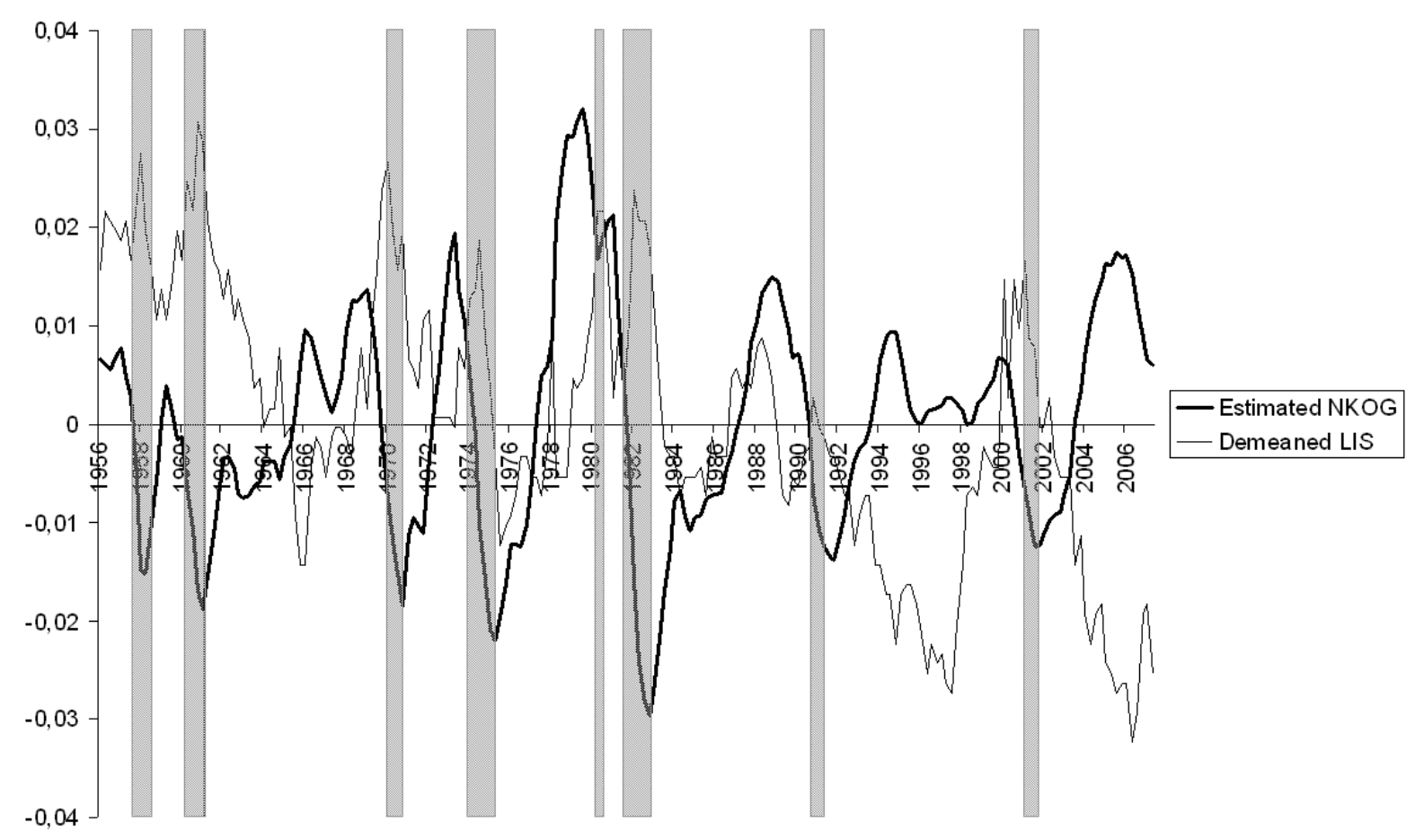

Figure 4: demeaned labor income share and smoothed NKOG. Shaded areas correspond with NBER recession dates

From this figure one can see that the labor income share has indeed spiked up in every post-war recession (except for the 1990/1 and 2001 ones), while it has shown enormous drops during the expansions of the 1990s and 2000s. Consequently, its 
behavior shows little resemblance to the NKOG estimate. In fact, its correlation with the NKOG estimate is with -0.2789 even negative! ${ }^{19}$ This suggests that the labor income share is a bad proxy for the NKOG.

\section{Robustness}

As I employ Bayesian estimation, the estimates presented in the previous section are the result of a combination of given data with imposed priors. Although the importance of these priors is likely to be relatively minor given the large number of observations used ( $c f$. Fernández-Villaverde and Rubio-Ramírez (2004)), this section checks the robustness of some key results to widening the priors. In addition, and perhaps more importantly, I also check the subsample stability of my results by focusing on the more homogeneous post-1982 sample period.

As surveyed in Schorfheide (2008), there is little consensus yet in the literature on the slope of the NKPC, $\kappa$. Part of this lack of consensus can be attributed to the sensitivity of the estimate of $\kappa$ with respect to the prior assumptions on $\varepsilon^{\pi}$ : the more freedom you give this shock, the more variation in inflation will be explained by it - and the lower the resulting estimate of $\kappa$ will be (see Lippi and Neri (2007)). Therefore, I have re-estimated the model after halving the prior mean for $\sigma_{\pi}$ to 0.005 - leaving all other parameters of the prior distributions unaffected. As the second column of Table 3 shows, none of the estimates changes significantly. More importantly, my NKOG estimate is not significantly different either: the correlation between my baseline gap estimate from Section 5 and the one obtained using the smaller prior mean for $\sigma_{\pi}$ equals 0.9997 .

Second, as the for- or backward lookingness of the NKPC is heavily debated (cf. GG (1999) vs. RW (2005a)), I have also estimated the model after imposing a uniform prior on $\gamma$ over the [0,1]-interval. As can be seen in the third column of Table 3, the results of this exercise are almost completely identical to those of the benchmark estimation in Section 5.1. We can thus conclude, in line with GG (1999), that there is a significant role for lagged inflation in the NKPC, but that forward lookingness dominates. Again, my NKOG estimate is not seriously affected by this robustness check: the correlation between the baseline gap estimate and the gap estimated under the uniform prior on $\gamma$ equals 0.9993 .

Finally, one may or may also not agree with my choice to consider the full sample

\footnotetext{
${ }^{19}$ As the labor income share is stationary, I assume that its steady state is equal to its mean as in GG (1999) and Sbordone (2002). Using the HP-filtered labor income share still results in a negative correlation, albeit a bit higher: -0.2011 .
} 
period from 1954 to 2008 as there seem to have been at least three monetary policy regimes in place over this period. ${ }^{20}$ Therefore, I have reestimated the benchmark model outlined in Section 4 on the much more homogeneous post-1982 sample, consisting of 103 quarterly observations. The result of this subsample stability check is shown in the last column of Table 3.

\begin{tabular}{|c|c|c|c|c|}
\hline & $\begin{array}{c}\text { Section } 5 \\
\text { Post. mean } \\
\text { (Standard devation) }\end{array}$ & $\begin{array}{c}\text { Smaller mean } \sigma_{\pi} \\
\text { Post. mean } \\
\text { (Standard devation) }\end{array}$ & $\begin{array}{c}\text { Uniform prior } \gamma \\
\text { Post. mean } \\
\text { (Standard devation) }\end{array}$ & $\begin{array}{c}\text { Post-1982 } \\
\text { Post. mean } \\
\text { (Standard devation) } \\
\end{array}$ \\
\hline$\gamma$ & $\begin{array}{c}0.3255 \\
(0.0293)\end{array}$ & $\begin{array}{c}0.3268 \\
(0.0294)\end{array}$ & $\begin{array}{c}0.3187 \\
(0.0306)\end{array}$ & $\begin{array}{c}0.1410 \\
(0.0474)\end{array}$ \\
\hline$\delta$ & $\begin{array}{c}0.7564 \\
(0.0366)\end{array}$ & $\begin{array}{c}0.7558 \\
(0.0355)\end{array}$ & $\begin{array}{c}0.7398 \\
(0.0361)\end{array}$ & $\begin{array}{c}0.8125 \\
(0.0309)\end{array}$ \\
\hline$\vartheta$ & $\begin{array}{c}0.8582 \\
(0.0524) \\
\end{array}$ & $\begin{array}{c}0.8573 \\
(0.0521) \\
\end{array}$ & $\begin{array}{c}0.8642 \\
(0.0509) \\
\end{array}$ & $\begin{array}{c}0.8798 \\
(0.0444) \\
\end{array}$ \\
\hline$\kappa$ & $\begin{array}{l}0.0013 \\
(0.0006)\end{array}$ & $\begin{array}{l}0.0014 \\
(0.0006)\end{array}$ & $\begin{array}{c}0.0012 \\
(0.0004)\end{array}$ & $\begin{array}{c}0.0080 \\
(0.0064)\end{array}$ \\
\hline$\sigma$ & $\begin{array}{l}7.2527 \\
(1.3134) \\
\end{array}$ & $\begin{array}{l}7.2460 \\
(1.3102)\end{array}$ & $\begin{array}{l}7.4490 \\
(1.2166)\end{array}$ & $\begin{array}{l}5.9098 \\
(1.2289)\end{array}$ \\
\hline $\bar{\phi}$ & $\begin{array}{l}1.3610 \\
(0.1396)\end{array}$ & $\begin{array}{l}1.3626 \\
(0.1392) \\
\end{array}$ & $\begin{array}{l}1.2435 \\
(0.1234)\end{array}$ & $\begin{array}{l}1.6367 \\
(0.1786) \\
\end{array}$ \\
\hline$\rho_{y}$ & $\begin{array}{c}0.9441 \\
(0.0316)\end{array}$ & $\begin{array}{c}0.9450 \\
(0.0300)\end{array}$ & $\begin{array}{c}0.9317 \\
(0.0287)\end{array}$ & $\begin{array}{c}0.9486 \\
(0.0311)\end{array}$ \\
\hline$\rho_{\zeta}$ & $\begin{array}{c}0.5355 \\
(0.0932)\end{array}$ & $\begin{array}{c}0.5302 \\
(0.0919)\end{array}$ & $\begin{array}{l}0.5312 \\
(0.0914)\end{array}$ & $\begin{array}{c}0.6416 \\
(0.1000)\end{array}$ \\
\hline$\sigma_{y}$ & $\begin{array}{c}0.0064 \\
(0.0007) \\
\end{array}$ & $\begin{array}{c}0.0064 \\
(0.0007) \\
\end{array}$ & $\begin{array}{c}0.0064 \\
(0.0007) \\
\end{array}$ & $\begin{array}{c}0.0033 \\
(0.0004) \\
\end{array}$ \\
\hline$\sigma_{\pi}$ & $\begin{array}{c}0.0072 \\
(0.0005)\end{array}$ & $\begin{array}{c}0.0071 \\
(0.0005)\end{array}$ & $\begin{array}{c}0.0073 \\
(0.0005)\end{array}$ & $\begin{array}{r}0.0067 \\
(0.0006)\end{array}$ \\
\hline$\sigma_{\zeta}$ & $\begin{array}{l}0.0032 \\
(0.0007)\end{array}$ & $\begin{array}{c}0.0032 \\
(0.0007)\end{array}$ & $\begin{array}{l}0.0032 \\
(0.0007)\end{array}$ & $\begin{array}{c}0.0024 \\
(0.0004)\end{array}$ \\
\hline$\overline{\sigma_{r}}$ & $\begin{array}{c}0.0086 \\
(0.0004) \\
\end{array}$ & $\begin{array}{c}0.0086 \\
(0.0004)\end{array}$ & $\begin{array}{c}0.0086 \\
(0.0004) \\
\end{array}$ & $\begin{array}{c}0.0051 \\
(0.0004) \\
\end{array}$ \\
\hline$\sigma_{\mu}$ & $\begin{array}{c}0.0030 \\
(0.0007)\end{array}$ & $\begin{array}{c}0.0029 \\
(0.0007)\end{array}$ & $\begin{array}{c}0.0032 \\
(0.0007)\end{array}$ & $\begin{array}{c}0.0027 \\
(0.0005)\end{array}$ \\
\hline
\end{tabular}

Table 3: posterior distributions of parameters - robustness checks

When comparing these results with the estimates obtained from the full sample (reproduced in Column 1 of Table 3), two differences seem noteworthy. First, the estimate of the backward looking coefficient in the NKPC $(\gamma)$ is significantly lower,

\footnotetext{
${ }^{20}$ The period from 1970 to 1982 was associated with rather high rates of inflation, while the beginning and end of the sample were characterized by much lower inflation rates (see Schorfheide $(2005,2008))$.
} 
pointing at a lower degree of inflation persistence since 1982. This is consistent with the findings of Taylor (2000) and Cogley and Sargent (2001) and casts doubt on the claim that a high degree of inflation persistence is a structural feature of the US economy. Second, the estimate of the central bank's reaction coefficient on inflation $(\phi)$ is now higher - confirming the widely held view that the Fed is more aggressive on inflation since the early 1980s.

But what are the implications of the changes resulting from the use of post-1982 data for the path of the estimated NKOG? Figure 5 compares the NKOG estimate using only post-1982 data, with the relevant part of the NKOG estimate from Section 5.2 (where the full sample was used in the estimation).

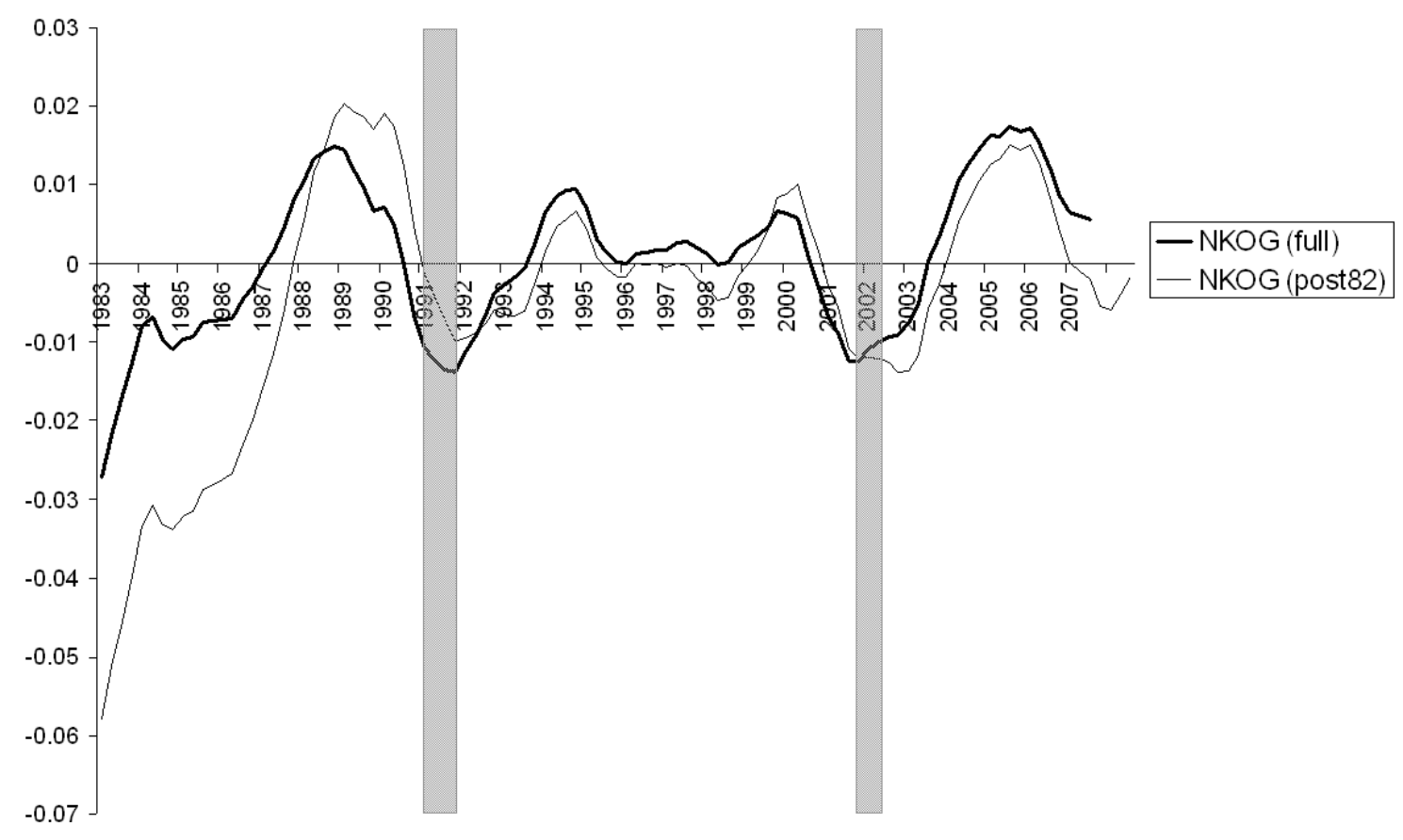

Figure 5: NKOG estimates obtained from estimation on full and post-1982 sample. Shaded areas correspond with NBER recession dates

As can be seen from this figure, the two NKOG estimates are pretty similar (apart from some apparent beginning of sample problems for the post-1982 estimate): the correlation coefficient between the two series equals 0.8327 . In addition, the post1982 estimate also turns negative during the two NBER recessions, tends to move in the same direction as the NKOG estimate based upon the full sample and both 
series reach their turning points around the same time. This suggests that the original NKOG estimate is robust to focusing on a more homogeneous sample period in terms of monetary policy and inflation.

\section{Relevance for the conduct of monetary policy}

Although the HP-filter is able to come up with a reasonable estimate of the NKOG over the past 55 years (see Figure 2), taking the model-based unobserved components approach may have important advantages for the conduct of monetary policy. The reason is threefold. First, the model-based approach seems able to guard itself against supply shock driven recessions (such as the 1980 one) to which monetary authorities should not respond by lowering interest rates (which they would be tempted to do if they would look at HP-filtered output).

Second, the approach taken in this paper can take output gap uncertainty into account (the gap estimate comes with credibility bands, displayed in the Appendix), which, as argued by Smets (2002), is useful if monetary authorities use restricted interest rate rules, such as the Taylor rule. In that case, monetary authorities would like to place less weight on poorly measured targets.

Third, output gap estimates obtained via univariate methods (such as the HPfilter or time detrending) have shown to be rather unreliable in real time, which is the only thing that is relevant for the conduct of monetary policy. As set out in a seminal paper by Orphanides and Van Norden (2002), this is primarily due to bad end-of-sample estimates of the trend in output. ${ }^{21}$ But as the approach adopted in this paper also uses information from forward looking variables, this could improve the real time performance of the NKOG estimate.

Figure 6 analyzes this conjecture. It shows three gap estimates for the homogeneous post-1982 sample period. First, it shows the smoothed post-1982 NKOG estimate discussed before, constructed by using information from both past and future observations. Consequently, this estimate is unavailable in real time. But as it uses all relevant information available, it is my best estimate of the truth.

\footnotetext{
${ }^{21}$ As Orphanides and Van Norden (2002) show that data revisions are of minor importance in explaining the unreliability of real time output gap estimates, I abstract from this issue here and focus exclusively on the end-of-sample problem.
} 


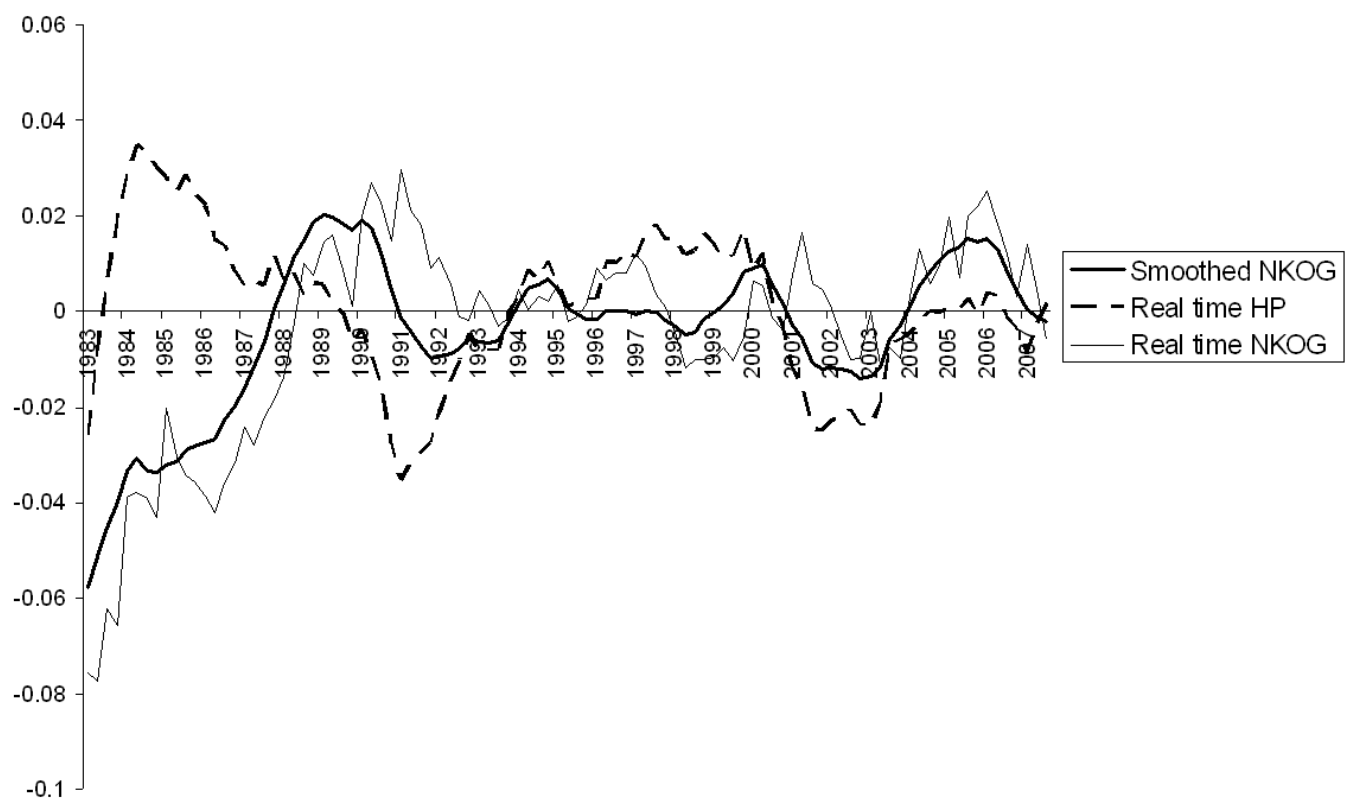

Figure 6: the NKOG estimate along with two real time estimates

Second, Figure 6 also shows the real time HP-gap estimate. This measure is constructed by rolling the HP-filter over the data series. Hence, the gap estimate at time $t$ is obtained by using past observations from period 1 to $t$ only (so I only use past data). ${ }^{22}$ As this one-sided approach does not make any use of future observations on the level of output, it is available in real time. But as Figure 6 shows, this comes at a significant cost: the correlation between the estimated (smoothed) NKOG and real time HP-filtered output drops to -0.1572 ! So although the HP-filter does a reasonable job in approximating the NKOG ex post, it fails miserably at this task in real time as it is then no longer able to exploit any information on the future path followed by GDP. This makes the HP-approach unsuited for the conduct of monetary policy, as emphasized before by Orphanides and Van Norden (2002).

But how about the real time performance of the model-based approach adopted in this paper? Do the addition of the information contained in the inflation rate (a forward looking variable) and the cross-equation restrictions imposed by the New Keynesian model really lead to better real time properties of the output gap estimate? Figure 6 gives the answer. It shows the filtered NKOG. This estimate is obtained in the same way as the smoothed NKOG estimate of Section 5, but uses past information

\footnotetext{
${ }^{22}$ Note that I use all past data available (starting in 1947Q1) to make sure that the HP-filter is not bothered by the well-known start-up problem it has.
} 
only. Consequently, this gap estimate is available in real time.

As can be seen from Figure 6, the model-based approach is indeed able to produce real time output gap estimates that are quite accurate: the correlation coefficient between the smoothed and filtered NKOG equals 0.8591 .

The simple eyeballing exercise for Figure 6 thus suggests that the model-based approach is able to come up with real time gap estimates that are more reliable (less subject to subsequent revisions) than those produced by the HP-filter. Following Orphanides and Van Norden (2002), one can analyze this conjecture more formally by looking at the revision errors of the different methods and comparing them with the actual NKOG. Table 4 contains the summary statistics of the various measures.

\begin{tabular}{||l||l||l||l||l||l||l||}
\hline \hline & $M E A N$ & $S D$ & $M I N$ & $M A X$ & $A R$ & $R M S$ \\
\hline \hline Smoothed NKOG & -0.0043 & 0.0161 & -0.0579 & 0.0203 & 0.9249 & - \\
\hline \hline HP revision & 0.0056 & 0.0242 & -0.0671 & 0.0309 & 0.9811 & 0.0245 \\
\hline \hline NKOG revision & 0.0000 & 0.0114 & -0.0260 & 0.0262 & 0.7757 & 0.0113 \\
\hline \hline
\end{tabular}

Table 4: summary NKOG and revision statistics ${ }^{23}$

The second row of Table 4 confirms the finding of Orphanides and Van Norden (2002) for the setting of this paper: the revision errors resulting from the use of the HP-filter to estimate the output gap in real time (which is equivalent to using a univariate unobserved components model for output; cf. Harvey and Jaeger (1993)) are very similar in size, volatility and time-series behavior to the actual gap itself. So again I find that HP-filtered output has bad real time properties, thereby giving rise to a serious policy problem.

The third row tells a different story, however. It contains the real time revision statistics for the NKOG estimate obtained via the method described in this paper. As can be seen from the table, the average revision error now equals zero and its standard deviation $(S D)$ is about 30 percent lower than that of the original series. Moreover, its coefficient of autocorrelation $(A R)$ as well as its range have fallen substantially. Finally, the root mean square of the revision errors $(R M S)$ has more than halved compared to its univariate competitor.

From the evidence presented in Figure 6 and Table 4 one may thus conclude that the multivariate method employed in this paper is more suited for real time analysis, than a univariate HP-filtering approach. This result stands in sharp contrast with

\footnotetext{
${ }^{23}$ In Table 4, "NKOG revision" is the series that consists of the difference between the smoothed NKOG estimate and its real time equivalent. "HP revision" is the series made up of the difference between the smoothed NKOG estimate and the real time HP gap estimate. The row labeled "Smoothed NKOG" simply displays the relevant statistics for my NKOG estimate.
} 
the original findings of Orphanides and Van Norden (2002). They concluded that "multivariate methods that incorporate information from inflation to estimate the output gap are not more reliable than their univariate counterparts". However, Orphanides and Van Norden (2002) only considered models in the spirit of Kuttner (1994), and as one may recall from the discussion in Section 3, this model just adds an ad hoc backward looking Phillips curve-like equation to a basic unobserved components model. The model developed in this paper on the other hand exploits the full structure of a microfounded and forward looking New Keynesian model and using the discipline imposed by the cross-equation restrictions of this model thus seems to pay off in the real time estimation of the NKOG. ${ }^{24}$

\section{Conclusion}

In this paper, I have presented a new way of estimating the New Keynesian model. By making use of an unobserved components approach, it is possible to feed raw data into the estimation procedure and to obtain model-consistent estimates of the natural level of output and the New Keynesian output gap.

It turns out that the behavior of the model implied New Keynesian output gap is not identical to time detrended or HP-filtered output. This is a result of the fact that all detrending/filtering methods considered impose a process for the natural level of output that is too smooth. However, as technology shocks only seem to have been of minor importance over the sample period in explaining business cycle fluctuations, the quantitative difference between the various output gap estimates is limited. In particular, the series for HP-filtered output is quite similar to that of the imputed series for the New Keynesian output gap: both tend to move in the same direction and roughly indicate the same periods as booms and recessions. ${ }^{25}$ Note however that this may change in the future if technology shocks happen to become of greater importance in driving business cycles.

The labor income share on the other hand is found to be a bad proxy for the New Keynesian output gap as its correlation with the New Keynesian output gap estimate is even negative.

\footnotetext{
${ }^{24}$ The usefulness of respecting cross-equation restrictions imposed by DSGE-models for forecasting purposes has been stressed before by for example Del Negro and Schorfheide (2004).

${ }^{25} \mathrm{~A}$ very similar conclusion is reached in independent, related work by Justiniano and Primiceri (2008), who also estimate the New Keynesian output gap via Bayesian methods. They however take a different modeling approach: rather than taking the unobserved components route, Justiniano and Primiceri (2008) handle the non-stationarity in output by estimating the system on first-differenced output.
} 
Finally, it is shown that the approach set out in this paper has better real time properties than the HP-filter: where the latter produces real time output gap estimates that are subject to significant subsequent revisions, the model-based approach manages to reduce the revision errors by about 50 percent. For that reason, as well as for the fact that it allows for supply shock driven recessions (to which monetary authorities should not respond by lowering interest rates) and as it can take output gap uncertainty into account, the model-based approach may be useful in the conduct of monetary policy.

\section{Appendix}

\subsection{Prior and posterior distributions}

Figure A2 shows the posterior mode (the dotted green line) along with the prior and posterior distributions of the variables estimated in Section 5.
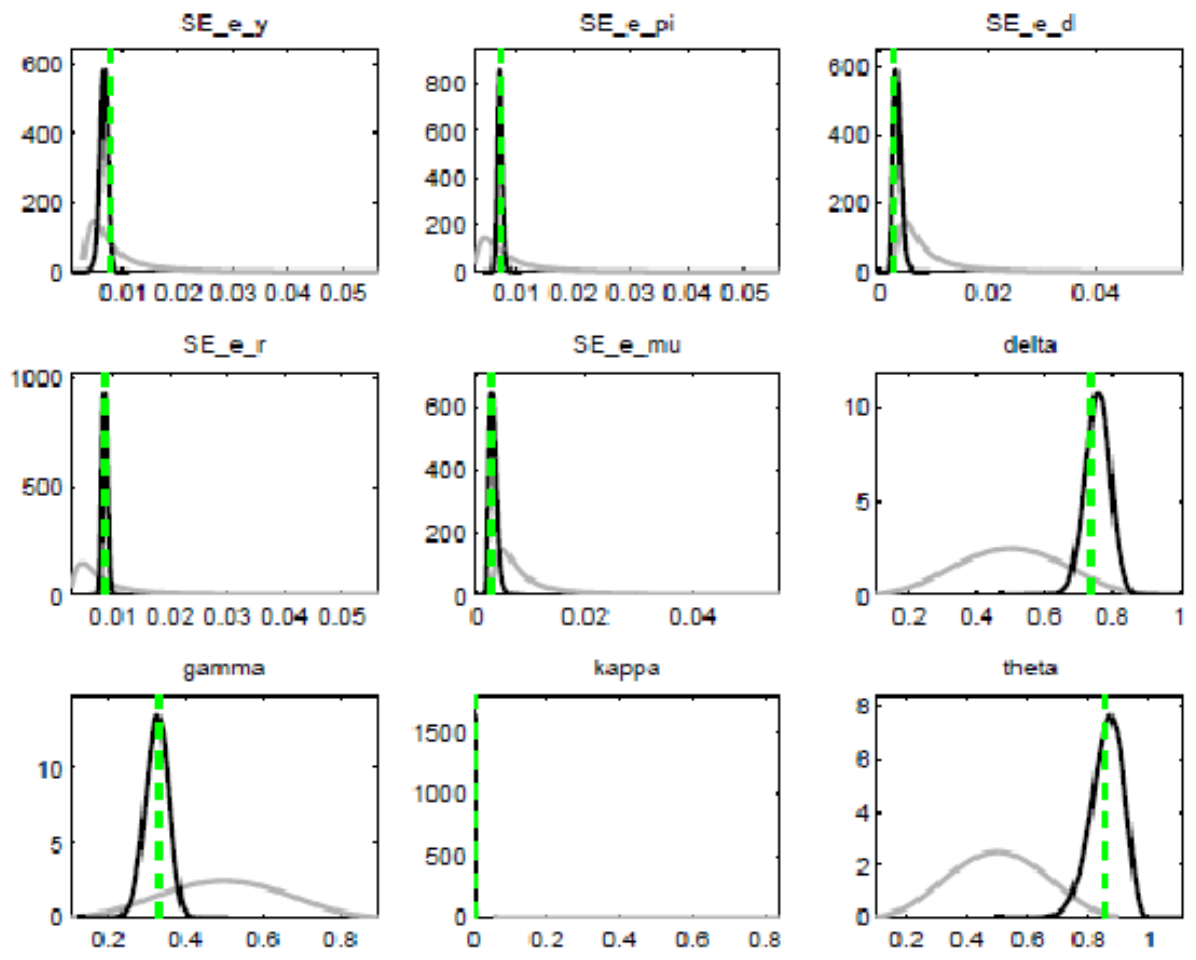

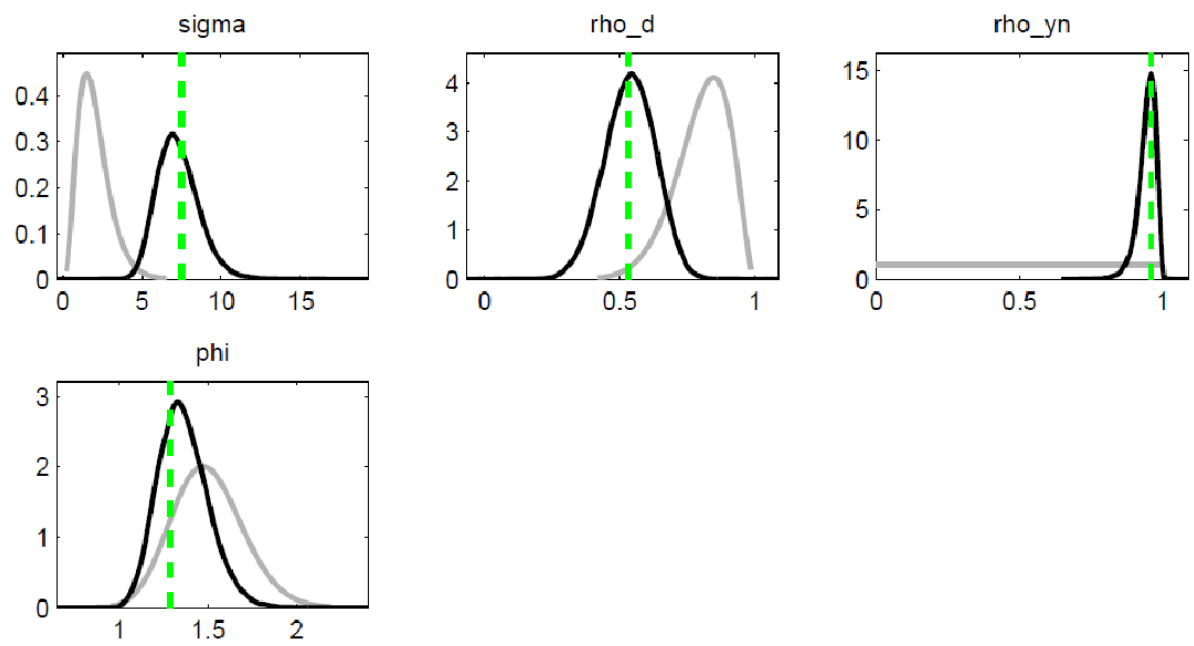

Figure A1: Prior and posterior distributions

\subsection{Credibility bands on NKOG estimate}

Figure A2 shows the 95 percent credibility bands of the NKOG estimated in Section 5.

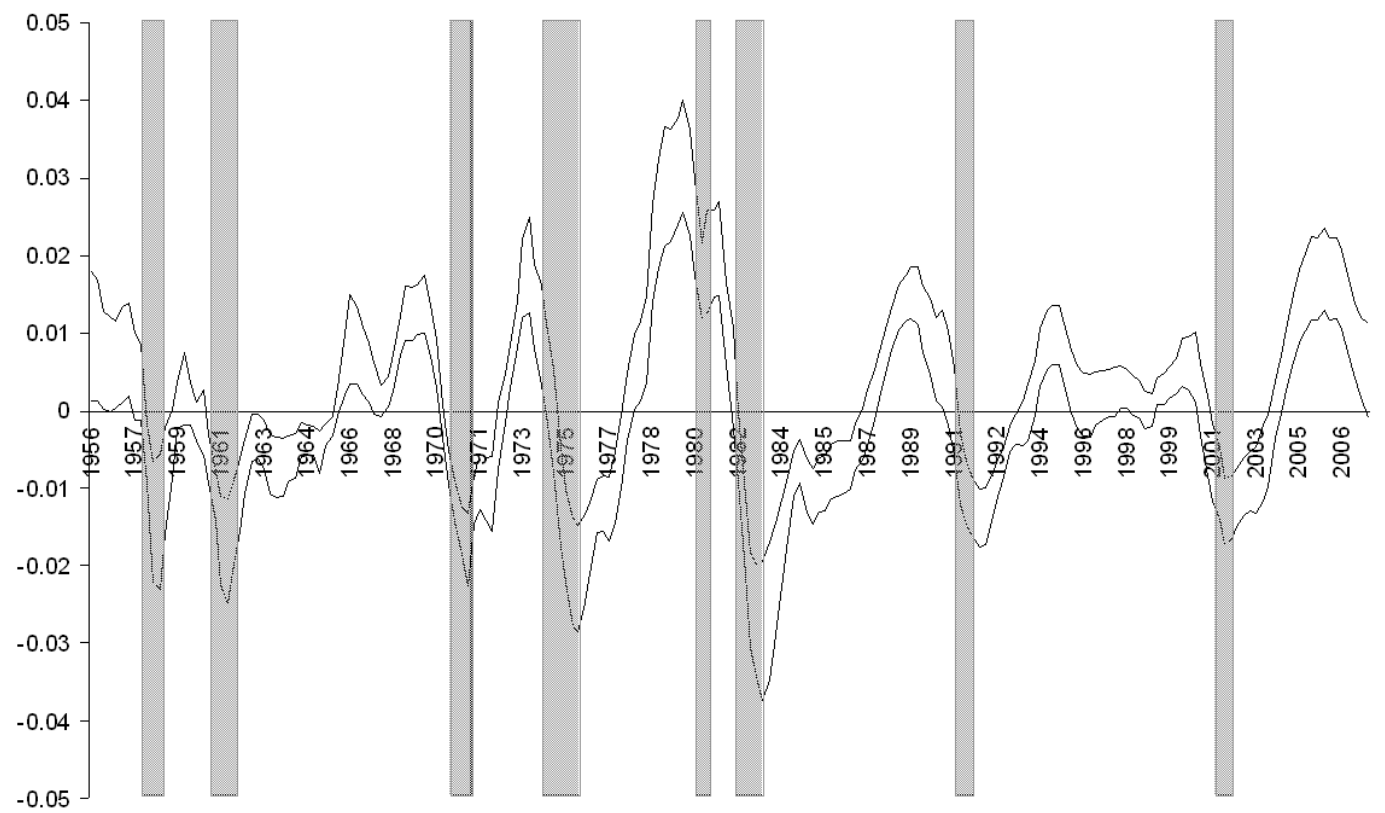

Figure A2: 95 percent credibility bands for estimated NKOG. Shaded areas correspond with NBER recession dates 


\section{References}

Bils, M. and J.A. Kahn (2000), "What inventory behavior tells us about business cycles", American Economic Review, 90 (3), pp. 458-481.

Boldrin, M., L.J. Christiano and J.D.M. Fisher (2001), "Habit persistence, asset returns, and the business cycle", American Economic Review, 91 (1), pp. 149-166.

Cho, S. and A. Moreno (2006), "A small-sample study of the New Keynesian macro model", Journal of Money, Credit and Banking, 38 (6), pp. 471-507.

Christiano, L.J., M. Eichenbaum and and C.L. Evans (2005), "Nominal rigidities and the dynamic effects of a shock to monetary policy", Journal of Political Economy, 113 (1), pp. 1-45.

Clarida, R. J. Galí and M. Gertler (2000), "Monetary policy rules and macroeconomic stability: Evidence and some theory", Quarterly Journal of Economics, 115 (1), pp. 147-180.

Clark, P. (1989), "Trend reversion in real output and unemployment", Journal of Econometrics, 40 (1), pp. 15-32.

Cogley, T. and T.J. Sargent (2001), "Evolving post-World War II US inflation dynamics", in: B. Bernanke and K. Rogoff (eds.), NBER Macroeconomics Annual 2001, Cambridge, MA.: MIT Press, pp. 331-373.

Cogley, T. and A. Sbordone (2008), "Trend inflation, indexation, and inflation persistence in the New Keynesian Phillips curve", American Economic Review, 98 (5), pp. 2101-2126.

DeJong, D.N. and C.H. Whiteman (1989), "Trends and cycles as unobserved components in real GNP: A Bayesian perspective", Journal of the American Statistical Association Papers and Proceedings, pp. 63-70.

Del Negro, M. and F. Schorfheide (2004), "Priors from General Equilibrium Models for VARs", International Economic Review, 45 (2), pp. 643-673.

Fernández-Villaverde, J. and J.F. Rubio-Ramírez (2004), "Comparing dynamic equilibrium models to data: A Bayesian approach", Journal of Econometrics, 123 (1), pp. 153-187.

Fuhrer, J.C. and G. Moore (1995), "Inflation persistence", Quarterly Journal of Economics, 110 (1), pp. 127-159.

Fuhrer, J.C. (2000), "Habit formation in consumption and its implications for monetary-policy models", American Economic Review, 90 (3), pp. 367-390.

Galí, J. (2008), Monetary Policy, Inflation and the Business Cycle: An Introduction to the New Keynesian Framework, Princeton, NJ and Oxford: Princeton University Press.

Galí, J. and M. Gertler (1999), "Inflation dynamics: A structural econometric 
analysis", Journal of Monetary Economics, 44 (2), pp. 195-222.

Galí, J., M. Gertler and J.D. Lopez-Salido (2005), "Robustness of the estimates of the hybrid New Keynesian Phillips curve", Journal of Monetary Economics, 52 (6), pp. 1107-1118.

Gerlach, S. and L.E.O. Svensson (2003), "Money and inflation in the euro area: A case for monetary indicators?", Journal of Monetary Economics, 50 (8), pp. 16491672 .

Harvey, A.C. (1985), "Trends and cycles in macroeconomic time series", Journal of Business \&6 Economic Statistics, 3 (3), pp. 216-227.

Harvey, A.C. and A. Jaeger (1993), "Detrending, stylized facts and the business cycle", Journal of Applied Econometrics, 8 (3), pp. 231-247.

Harvey, A.C., T.M. Trimbur and H.K. van Dijk (2007), "Trends and cycles in economic time series: A Bayesian approach", Journal of Econometrics, 140 (2), pp. 618-649.

Hodrick, R.J. and E.C. Prescott (1997), "Postwar US business cycles: An empirical investigation", Journal of Money, Credit and Banking, 29 (1), pp. 1-16.

Ireland, P.N. (2001), "Sticky price models of the business cycle: Specification and stability", Journal of Monetary Economics, 47 (1), pp. 3-18.

Ireland, P.N. (2004), "A method for taking models to the data", Journal of Economic Dynamics and Control, 28 (6), pp. 1205-1226.

Justiniano, A. and G.E. Primiceri (2008), "Potential and natural output", mimeo.

King, R.G. and M.W. Watson (1996), "Money, prices, interest rates and the business cycle", Review of Economics and Statistics, 78 (1), pp. 35-53.

Kuttner, K.N. (1994), "Estimating potential output as a latent variable", Journal of Business \& Economic Statistics, 12 (3), pp. 361-368.

Lindé, J. (2005), "Estimating New-Keynesian Phillips curves: A full information maximum likelihood approach", Journal of Monetary Economics, 52 (6), pp. 11351149.

Lippi, F. and S. Neri (2007), "Information variables for monetary policy in an estimated structural model of the euro area", Journal of Monetary Economics, 54 (4), pp. 1256-1270.

Lubik, T.A. and F. Schorfheide (2004), "Testing for indeterminacy: An application to US monetary policy", American Economic Review, 94 (1), pp. 190-217.

Neiss K.S. and E. Nelson (2003), "The real-interest-rate gap as an inflation indicator", Macroeconomic Dynamics, 7 (2), pp. 239-262.

Neiss K.S. and E. Nelson (2005), "Inflation dynamics, marginal cost, and the output gap: evidence from three countries", Journal of Money, Credit, and Banking, 37 (6), pp. 1019-1045. 
Nelson, C.R. and C.I. Plosser (1982), "Trends and random walks in macroeconomic time series", Journal of Monetary Economics, 10 (2), pp. 139-162.

Orphanides, A. and S. van Norden (2002), "The unreliability of output gap estimates in real-time", Review of Economics and Statistics, 84 (4), pp. 569-583.

Perron, P. (1989), "The great crash, the oil price shock, and the unit root hypothesis", Econometrica, 57 (6), pp. 1361-1401.

Planas, C., A. Rossi and G. Fiorentini (2008), "Bayesian analysis of the output gap", Journal of Business 83 Economic Statistics, 26 (1), pp. 18-32.

Rabanal, P. and J.F. Rubio-Ramírez (2005), "Comparing New Keynesian models of the business cycle: A Bayesian approach", Journal of Monetary Economics, 52 (6), pp. 1151-1166.

Rotemberg, J.J. and M. Woodford (1999), "The cyclical behavior of prices and costs", NBER Working Paper No. 6909.

Rudd, J. and K. Whelan (2005a), "Does labor's share drive inflation?", Journal of Money, Credit and Banking, 37 (2), pp. 297-312.

Rudd, J. and K. Whelan (2005b), "New tests of the New-Keynesian Phillips curve", Journal of Monetary Economics, 52 (6), pp. 1167-1181.

Rudd, J. and K. Whelan (2007), "Modelling inflation dynamics: A critical survey of recent research", Journal of Money, Credit and Banking, 39 (1), pp. 155-170.

Sbordone, A.M. (2002), "Prices and unit labor costs: A new test of price stickiness", Journal of Monetary Economics, 49 (2), pp. 265-292.

Sbordone, A.M. (2005), "Do expected marginal costs drive inflation dynamics?", Journal of Monetary Economics, 52 (6), pp. 1183-1197.

Schorfheide, F. (2005), "Learning and monetary policy shifts", Review of Economic Dynamics, 8 (2), pp. 392-419.

Schorfheide, F. (2008), "DSGE model-based estimation of the New Keynesian Phillips curve", Federal Reserve Bank of Richmond Economic Quarterly, 94 (4), pp. 397-433.

Smets, F. (2002), "Output gap uncertainty: Does it matter for the Taylor rule?", Empirical Economics, 27 (1), pp. 113-129.

Smets, F. and R. Wouters (2003), "An estimated dynamic stochastic general equilibrium model of the euro area", Journal of the European Economic Association, 1 (5), pp. 1123-1175.

Smets, F. and R. Wouters (2007), "Shocks and frictions in US business cycles: A Bayesian DSGE approach", American Economic Review, 97 (3), pp. 586-606.

Taylor, J.B. (1993), "Discretion versus policy rules in practice", Carnegie-Rochester Series on Public Policy, 39, pp. 195-214. 
Taylor, J.B. (2000), "Low inflation, pass-through, and the pricing power of firms", European Economic Review, 44 (7), pp. 1389-1408.

Watson, M.W. (1986), "Univariate detrending methods with stochastic trends", Journal of Monetary Economics, 18 (1), pp. 49-75.

Weber, C.E. (1995), "Cyclical output, cyclical unemployment, and Okun's coefficient: A new approach", Journal of Applied Econometrics, 10 (4), pp. 433-445. 